\title{
Effect of sintering temperature and porosity on electro- deoxidation of calcium titanate in $\mathrm{CaCl}_{2}-\mathrm{NaCl}$ molten salt
}

\author{
Guoli Zhao, Ying Xu, Yanqing Cai ${ }^{*}$ \\ College of Materials Science and Engineering, North China University of Science and Technology, \\ Hebei, Tangshan 063210, China \\ *E-mail: caiyanqing126@126.com
}

Received: 5 November 2021 / Accepted: 17 December 2021 / Published: 5 January 2022

\begin{abstract}
The performance of cathodes has an important influence on the degree of deoxidation when preparing titanium via a molten salt electro-deoxidation process. In this study, $\mathrm{CaTiO}_{3}$ was used as a cathode to investigate the influence of sintering temperature on the degree of electro-deoxidation. The results show that increasing the sintering temperature from $900{ }^{\circ} \mathrm{C}$ to $1200{ }^{\circ} \mathrm{C}$ can effectively improve the conductivity of a $\mathrm{CaTiO}_{3}$ cathode, which is conducive to electron migration. However, a high temperature $\left(1300^{\circ} \mathrm{C}\right)$ leads to excessive grain growth, increasing the solid phase transport distance for $\mathrm{O}^{2-}$, which is not conducive to deep reduction of the cathode. When sintered at $1200^{\circ} \mathrm{C}$, the $\mathrm{CaTiO}_{3}$ cathode shows the most in-depth deoxidation, which is suitable for electro-deoxidation of the precursor to prepare titanium. In addition, the effect of porosity on the degree of deoxidation was also studied. When the $\mathrm{NH}_{4} \mathrm{HCO}_{3}$ content increases from $2 \%$ to $10 \%$, the porosity is increased, which leads to a decrease in the mechanical strength of the cathode, and a part of the cathode becomes detached from the matrix during the electrolysis process, leading to failure of the reduction reaction. Moreover, a considerable amount of unreacted $\mathrm{CaTiO}_{3}$ is present in the cathode product with $10 \mathrm{wt} \% \mathrm{NH}_{4} \mathrm{HCO}_{3}$ because the cathode with high porosity produces cracks in the electrolytic process. By comparing the deoxidation effect before and after adding $2 \% \mathrm{NH}_{4} \mathrm{HCO}_{3}$ under optimal conditions, $\mathrm{CaTiO}_{3}$ cathodes sintered at $1200^{\circ} \mathrm{C}$ without $\mathrm{NH}_{4} \mathrm{HCO}_{3}$ were found to be thoroughly electrolysed, with the purity of the titanium obtained reaching $97.65 \%$.
\end{abstract}

Keywords: Molten salt electro-deoxidation, sintering temperature, porosity, titanium.

\section{$\underline{\text { FULL TEXT }}$}

(C) 2022 The Authors. Published by ESG (www.electrochemsci.org). This article is an open access article distributed under the terms and conditions of the Creative Commons Attribution license (http://creativecommons.org/licenses/by/4.0/). 